\title{
Dosimetric and Radiobiological Evaluation of Radiation-induced Pulmonary Toxicity in the Esophageal Malignancy Using VMAT
}

\author{
(1) Sanjib GAYEN, (1) Shekhar ANAND, (1) Sumanta MANNA, Sri Harsha KOMBATHULA, \\ (1) Sweta SONI, (1) Akanksha SOLANKI, (1) Sonal VARSHNEY, (1) Puneet PAREEK
}

Department of Radiation Oncology, All India Institute of Medical Sciences, Rajasthan-India

\begin{abstract}
OBJECTIVE
The incidence of radiation-induced pneumonitis after radiotherapy treatment of esophageal malignancy is of great concern. The study aims to evaluate the feasibility, assessing the risk of radiation pneumonitis (RP) with dosimetric and radiobiological outcomes treated with volumetric modulated arc therapy (VMAT) in esophageal cancer patients.
\end{abstract}

\section{METHODS}

Twenty patients of esophageal cancer that had received radiotherapy using VMAT in our department were retrospectively analyzed. Each of the patient's treatment plan was analyzed with conformity index $\left(\mathrm{CI}_{\mathrm{RTOG}}\right)$, volume covering $95 \%$ isodose line $\left(\mathrm{V}_{95 \%}\right)$, isodose line covering $95 \%$ of the target $\left(\mathrm{ID}_{95 \%}\right)$, dose homogeneity index (DHI), low-dose volume of the organs-at-risks (OARs), normal tissue complication probability (NTCP), and risk factor (RF) of the OARs.

\section{RESULTS}

The prescription dose ranged from 45 to $54 \mathrm{~Gy}$. The mean value of $\mathrm{CI}_{\mathrm{RTOG}}, \mathrm{V}_{95 \%}, \mathrm{ID}_{95 \%}, \mathrm{DHI}$, total MU, and the intensity-modulated radiation therapy ratio was $1.12 \pm 0.07,96.58 \pm 2.43 \%, 95.57 \pm 2.48 \%, 0.92 \pm 0.03$, $741.50 \pm 135.50$, and $4.01 \pm 0.72$, respectively. The median value of NTCP was 0.17 . The observed value of $\mathrm{RF}$ in the lung and heart was $0.61 \pm 0.13$ and $0.86 \pm 0.43$, respectively.

\section{CONCLUSION}

The VMAT technique reduces the toxicity rate of the patient and the dosimetric as well as the radiobiological parameters with the quantitative analysis of dose-volume parameters such as $\mathrm{D}_{\text {mean }}, \mathrm{V}_{20 \mathrm{~Gy}}, \mathrm{RF}$, and NTCP may be used to assess the probability of post-radiotherapy RP.

Keywords: Esophageal cancer; radiation pneumonitis; radiotherapy; VMAT. Copyright $\odot$ 2022, Turkish Society for Radiation Oncology

\section{Introduction}

The probability of developing radiation pneumonitis (RP) after treatment with high-dose radiotherapy is becoming one of the main limiting factors when escalating radiation dose for esophageal cancer.[1] The development of pulmonary complications such as pneumonitis and lung fibrosis is due to excessive radiation dose to the normal lungs in close proximity to the target region, causing life-threatening events or deaths. [2-4] Furthermore, the studies from the past have indicated the correlation between radiation-induced lung 
toxicities to the pre-existing cardiac morbidity or concomitant radiation to the heart. $[5,6]$

Esophageal carcinoma is the eighth most commonly diagnosed malignancy with an annual incidence of 456,000 new cases (3 4\% of all cancers) and the sixth leading cause of cancer-related death globally.[7] In Asian countries, squamous cell carcinoma is the most common type of esophageal malignancy, associated with significant tobacco and alcohol use.[8] Neoadjuvant chemoradiotherapy (CRT) followed by surgical resection is one of the standard treatments of esophageal cancer, if operable in the absence of medical contraindications. Definitive CRT is another treatment modality with curative intent for unresectable tumors. [9] Radiotherapy has been the mainstay of treatment in the management of this diverse spectrum of esophageal malignancies, particularly diagnosed at an advanced stage with a higher risk of failure at the local site. $[10,11] \mathrm{Ra}$ diotherapy aims to maximize the dose to the target with adequate margins while potentially decreasing dose to the nearby normal healthy tissues in the tumor vicinity, improving local control and survival. In the radical scheme of treatment of esophageal carcinoma, volumetric modulated arc therapy (VMAT), a special variant of intensity-modulated radiation therapy (IMRT), was found to provide similar conformity, homogeneity, and avoiding excess dose to the organ-at-risk (OAR) when compared to fixed field IMRT or 3-dimensional conformal radiation therapy (3D-CRT), with a corresponding improvement in delivery efficiency.[4,12-14]

With this background, we undertook a retrospective analysis of the patients of esophageal malignancy treated in our center to evaluate the feasibility of treatment using VMAT and assessing the probability of radiation-induced lung toxicity with dosimetric parameters and radiobiological outcomes by calculating normal tissue complication probability (NTCP).

\section{Materials and Methods}

\section{Patient Demographics}

From 2018 to 2019, 20 patients of histologically confirmed esophageal cancer, received radiotherapy in our department were retrospectively analyzed. Only patients with no distant metastases and treated with VMAT planning were included in this study. All of them received radical, adjuvant, or neoadjuvant radiation therapy with curative intent up to a median dose of $50 \mathrm{~Gy}$, ranging from 45 to $54 \mathrm{~Gy}$ at 1.8 to 2 Gy dose per fraction, delivered based on their clinical stage, over
4-5 weeks (five fractions per week) by a clinical linear accelerator (LINAC), following International Commission on Radiation Units and Measurements (ICRU) recommendations, either alone or in combination with concomitant chemotherapy (chemoradiation).

All patients were scanned on a 16-slice computed tomography (CT) simulator (Optima 580, GE Healthcare, Waukesha, USA) with a helical acquisition of 2.5 mm slice thickness, positioned supine and arms above their heads while breathing freely for volume delineation and dose computation. Following the ICRU guidelines, the gross tumor volume defined based on primary tumor and clinically positive lymph nodal extensions based on endoscopic, CT, or PET-CT findings. The clinical target volumes (CTVs) were contoured giving $1 \mathrm{~cm}$ radial margin and $4 \mathrm{~cm}$ craniocaudal margin adjusting to the natural anatomic barriers with no microscopic expansion of the disease. The planning target volumes (PTVs) of each of the patients included the CTV with a $5 \mathrm{~mm}$ margin uniformly in all directions.[15] All the organs were contoured according to the Radiation Therapy Oncology Group (RTOG) atlas for normal tissue contouring.[16] The contoured critical organs retrospectively analyzed were bilateral lungs, heart, and spinal cord for this study. Patient characteristics and dose prescriptions are described in Table 1.

\section{Patient Treatment Planning}

Clinical plans were generated using VMAT based on Monte Carlo dose calculation algorithm with a grid size of $0.3 \mathrm{~cm}$ and $2 \%$ calculation uncertainty on Monaco (V5.11.02) (Elekta CMS, Sunnyvale, CA) treatment planning system (TPS) using $6 \mathrm{MV}$ flat photon beam with the maximum dose rate of $600 \mathrm{cGy} / \mathrm{min}$ at Dmax. Each of the patients was planned using three coplanar beam orientations, associated with achievable gantry-couch-patient clearance using an optimized number of treatment arcs, gantry angles, and fluences. The $1^{\text {st }}$ arc was starting from $180^{\circ}$ to $130^{\circ}, 2^{\text {nd }}$ one from $50^{\circ}$ to $310^{\circ}$, and last $3^{\text {rd }}$ arc from $230^{\circ}$ to $180^{\circ}$ with a double arc plan (clockwise and anti-clockwise direction). The typical beam arrangements for an example case are illustrated in Figure 1. All clinical plans were optimized based on the clinical objectives to achieve optimum target coverage with dose sparing to the nearby OARs. All treatment plans were delivered on Elekta Versa HD (Elekta, Crawley, UK) equipped with 160 leaves Agility MLC of $5 \mathrm{~mm}$ leaf thickness at the isocenter and qualitatively evaluated for each patient assessing the dose-volume histogram (DVH) parameters for all critical organs and target volume. 


\begin{tabular}{|c|c|c|}
\hline Variables & $\mathbf{n}$ & $\%$ \\
\hline \multicolumn{3}{|l|}{ Age (year) } \\
\hline Median & 57 & \\
\hline Range & $32-76$ & \\
\hline \multicolumn{3}{|l|}{ Sex } \\
\hline Male & 10 & 50 \\
\hline Female & 10 & 50 \\
\hline \multicolumn{3}{|l|}{ Residence } \\
\hline Urban & 15 & 75 \\
\hline Rural & 5 & 25 \\
\hline \multicolumn{3}{|l|}{ Histology } \\
\hline Squamous cell carcinoma & 19 & 95 \\
\hline Adenocarcinoma & 1 & 5 \\
\hline \multicolumn{3}{|l|}{ Stage } \\
\hline II & 1 & 5 \\
\hline III & 12 & 60 \\
\hline IVA & 7 & 35 \\
\hline \multicolumn{3}{|l|}{ GTV length $(\mathrm{cm})$} \\
\hline$<8$ & 13 & 65 \\
\hline$\geq 8$ & 7 & 35 \\
\hline \multicolumn{3}{|l|}{ Tumor location } \\
\hline Upper thoracic & 2 & 10 \\
\hline Middle thoracic & 7 & 35 \\
\hline Lower thoracic & 11 & 55 \\
\hline \multicolumn{3}{|l|}{ Radiation dose (Gy) } \\
\hline 45 & 8 & 40 \\
\hline$>45$ and $\leq 50.4$ & 11 & 55 \\
\hline$>50.4$ & 1 & 5 \\
\hline
\end{tabular}

GTV: Gross tumor volume; Gy: Gray

\section{Dosimetric and Radiobiological Parameters}

According to the ICRU 83 report, 95\% of PTV volume should receive $95 \%$ of the prescribed dose. The conformity index $\left(\mathrm{CI}_{\mathrm{RTOG}}\right)$,[17] volume receiving $95 \%$ isodose line, isodose line covering $95 \%$ volume of the target, and dose homogeneity index[18] for target volume were analyzed. Total monitor units (MUs) per fraction and IMRT ratio, that is, total MU per cGy prescription dose for each clinically accepted plan were noted. For OARs, $\mathrm{D}_{\text {max }}, \mathrm{D}_{\text {mean }}$, and dose covering a percentage of the structure's volume $\left(\mathrm{D}_{\%}\right)$, for example, $\mathrm{D}_{10 \%}$ and $\mathrm{D}_{35 \%}$, and similarly, the percentage volume of the structure receiving a certain dose $\left(\mathrm{V}_{\mathrm{Gy}}\right)$, for example, $\mathrm{V}_{5 \mathrm{~Gy}}$, $\mathrm{V}_{10 G y}, \mathrm{~V}_{13 G y}, \mathrm{~V}_{20 \mathrm{~Gy}}, \mathrm{~V}_{25 \mathrm{~Gy} y}, \mathrm{~V}_{30 \mathrm{G} y}$, and $\mathrm{V}_{40 \mathrm{~Gy}}$ were recorded for dosimetric evaluation and planning purposes and verified with quantitative analyses of normal tissue effects in the clinic (QUANTEC) guidelines.[19]

A comprehensive evaluation tool risk factor conformity index (RFC), enclosing clinical, dosimetric parameters, isodose line, and OARs tolerance doses
Table 2 Summary of the quantitative analysis of physical treatment planning parameters and dosevolume histogram (DVH) of the target volumes and organ-at-risk in the patients

\begin{tabular}{|c|c|}
\hline Parameter & Mean \pm SD \\
\hline \multicolumn{2}{|l|}{ PTV } \\
\hline Volume (cc) & $636.69 \pm 281.41$ \\
\hline $\mathrm{Cl}_{\text {RTOG }}$ & $1.12 \pm 0.07$ \\
\hline $\mathrm{V}_{95 \%}(\%)$ & $96.58 \pm 2.43$ \\
\hline $\mathrm{ID}_{95 \%}(\%)$ & $95.57 \pm 2.48$ \\
\hline $\mathrm{DHI}$ & $0.92 \pm 0.03$ \\
\hline \multicolumn{2}{|l|}{ Treatment plan } \\
\hline MU & $741.50 \pm 135.50$ \\
\hline IMRT ratio & $4.01 \pm 0.72$ \\
\hline \multicolumn{2}{|l|}{ Organ-at-risk } \\
\hline \multicolumn{2}{|l|}{ Combined lung } \\
\hline$V_{5 G y}(\%)$ & $62.92 \pm 13.39$ \\
\hline $\mathrm{V}_{10 \mathrm{~Gy}}(\%)$ & $47.80 \pm 9.51$ \\
\hline $\mathrm{V}_{13 \mathrm{~Gy}}(\%)$ & $39.78 \pm 6.90$ \\
\hline $\mathrm{V}_{20 \mathrm{~Gy}}(\%)$ & $25.24 \pm 4.72$ \\
\hline $\mathrm{V}_{25 G \mathrm{y}}(\%)$ & $18.02 \pm 4.78$ \\
\hline $\mathrm{V}_{30 \mathrm{~Gy}}(\%)$ & $12.58 \pm 4.22$ \\
\hline $\mathrm{V}_{40 \mathrm{~Gy}}(\%)$ & $4.98 \pm 2.02$ \\
\hline$D_{\max }(G y)$ & $52.51 \pm 2.93$ \\
\hline $\mathrm{D}_{\text {mean }}(\mathrm{Gy})$ & $13.23 \pm 2.35$ \\
\hline \multicolumn{2}{|l|}{ Heart mean } \\
\hline $\mathrm{V}_{25 \mathrm{~Gy}}(\%)$ & $47.99 \pm 21.14$ \\
\hline $\mathrm{V}_{30 \mathrm{~Gy}}(\%)$ & $35.82 \pm 16.32$ \\
\hline$D_{10 \%}(G y)$ & $41.88 \pm 10.42$ \\
\hline$D_{\text {mean }}(G y)$ & $24.44 \pm 8.51$ \\
\hline \multicolumn{2}{|l|}{ Spinal cord } \\
\hline$D_{\max }(G y)$ & $39.48 \pm 3.98$ \\
\hline \multicolumn{2}{|l|}{ NTCP } \\
\hline Combined: Lung and heart & $0.16 \pm 0.04$ \\
\hline
\end{tabular}

PTV: Planning target volume; SD: Stardard deviation; $\mathrm{Cl}_{\text {RTOG }}$ : Conformity index (according to RTOG); $\mathrm{V}_{95 \%}$ : Volume receiving $95 \%$ isodose line; $\mathrm{ID}_{95 \%}$ : Isodose line covering $95 \%$ volume of the target; $\mathrm{DHI}$ : Dose homogeneity index; MU: Monitor unit; IMRT ratio: Intensity-modulated radiation therapy ratio; $D_{\alpha}$ : The dose covering a particular percentage of the structure's volume; $D^{\circ}$ and $D$ : The maximum point dose and mean dose for a volume; $\mathrm{V}_{G y}:$ The volume of the structure receiving a certain dose; NTCP: Normal tissue complication probability; Gy: Gray

was used for the assessment of possible damage in a particular organ which includes CI of the target and risk factor (RF) for a particular organ.[20] The formula used for the evaluation of the RFC was

$$
\begin{aligned}
& \mathrm{CI}=\mathrm{V}_{\mathrm{RI}} / \mathrm{V}_{\mathrm{T}} \\
& \mathrm{RF}=\mathrm{D}_{\mathrm{P}} \times\left\{\left(\mathrm{V}_{\mathrm{VOI}}\right) /\left(\mathrm{V}_{\mathrm{TVO}} \times \mathrm{D}_{\mathrm{TDO}}\right)\right\} \\
& \mathrm{RFC}=\left[\left(\mathrm{V}_{\mathrm{RI}} / \mathrm{V}_{\mathrm{T}}\right)+\mathrm{D}_{\mathrm{P}} \mathrm{X}\left\{\left(\mathrm{V}_{\mathrm{VOI}}\right) /\left(\mathrm{V}_{\mathrm{TVO}} \times \mathrm{D}_{\mathrm{TDO}}\right)\right\}\right] ;
\end{aligned}
$$

that is, $\mathrm{RFC}=\mathrm{CI}+\mathrm{RF}$, where, $\mathrm{V}_{\mathrm{RI}}$ is the volume of the reference isodose line, $\mathrm{V}_{\mathrm{T}}$ is the target volume, $\mathrm{D}_{\mathrm{P}}$ is the prescribed dose to the PTV, $\mathrm{V}_{\mathrm{VOI}}$ is the irradiated volume of the organ (organ's volume - reference iso- 

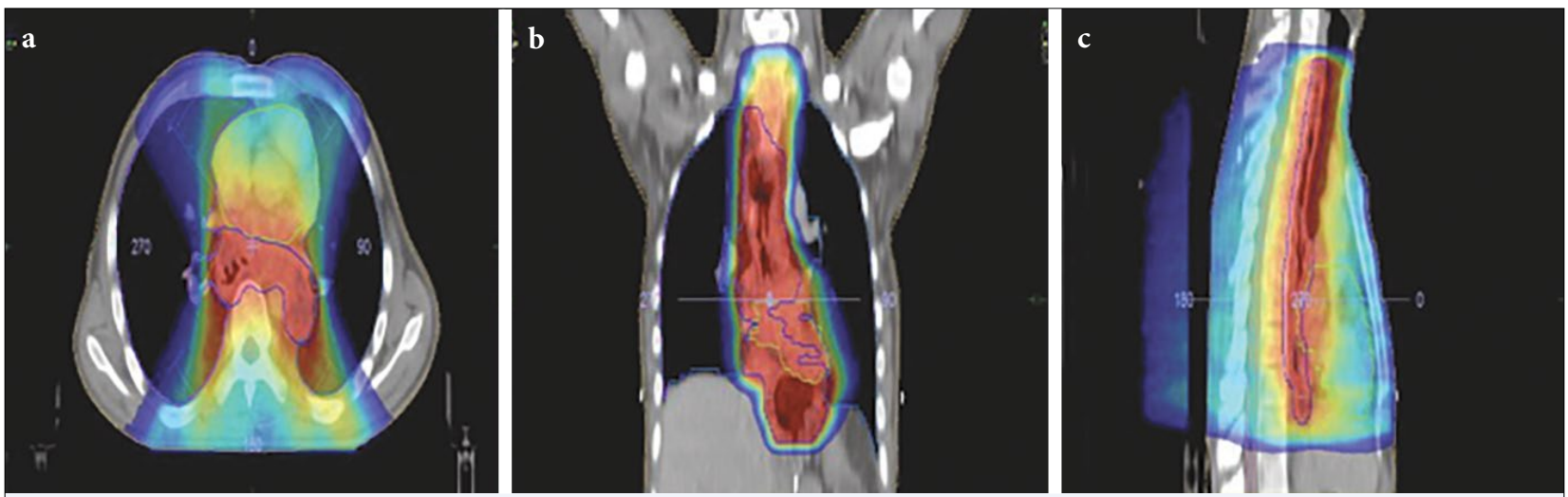

Fig. 1. The typical beam arrangements with (a) axial, (b) coronal, and (c) sagittal plane for an example case with a dose color wash display ranging from $10 \mathrm{~Gy}$ to $50 \mathrm{~Gy}$, respectively.

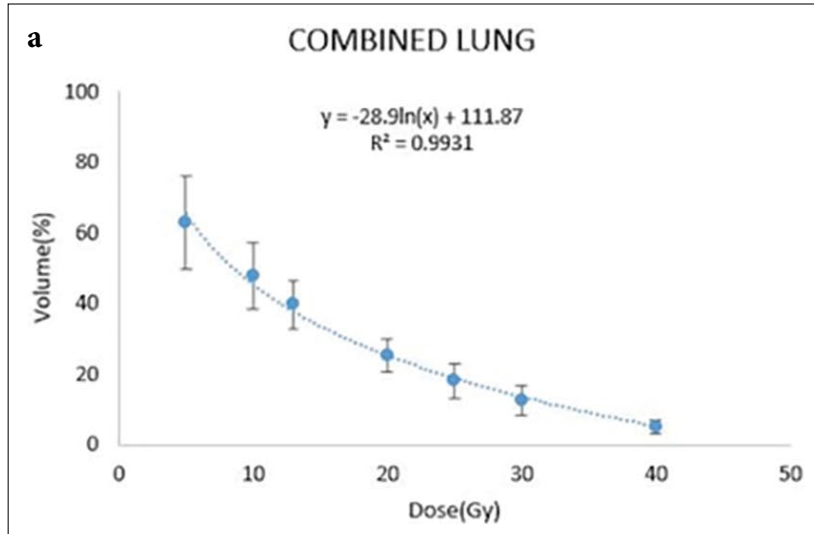

b

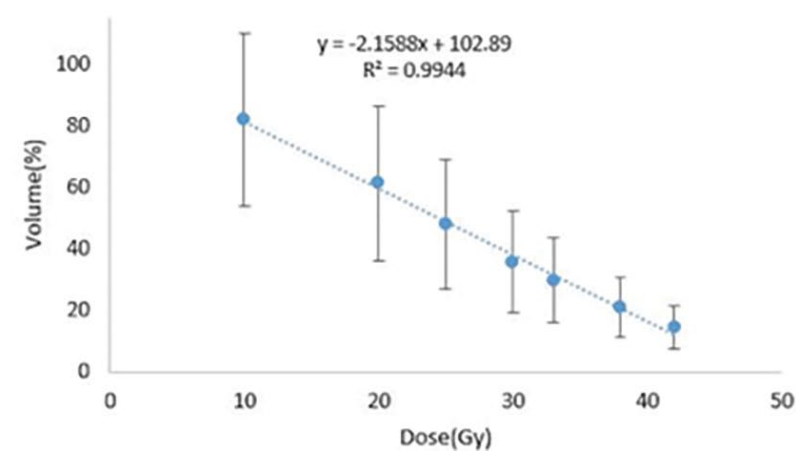

Fig. 2. Summary of the dose fall-off curve of (a) combined lung and (b) heart.

dose volume), $\mathrm{V}_{\mathrm{TVO}}$ is the total volume of the organ, and $\mathrm{D}_{\mathrm{TDO}}$ is the tolerance dose of that vital organ.

In addition, to calculate the predicted risk of RP in these patients, we used a combined heart and lung irradiation model and evaluated the NTCP depending on $\mathrm{D}_{10 \%}$ of the heart $\left(\mathrm{D}_{10}-\mathrm{H}\right)$ and $\mathrm{D}_{\text {mean }}$ of combined lung volume (MLD) [6] as,

$$
\begin{aligned}
& \mathrm{NTCP}=\frac{1}{1+\exp (-\mathrm{x})} \\
& \text { where, } \mathrm{x}=0.0234 \times \mathrm{D}_{10} \mathrm{H}+0.0649 \times \mathrm{MLD}-3.5 .
\end{aligned}
$$

\section{Statistical Analysis}

Statistical comparison of planning parameters and dose to the OARs in the VMAT plans was performed using SPSS, a data analysis software. As all the variables are quantitative, each of them was denoted by their respective means with standard deviation or with their ranges and analyzed statistically using the one-sample t-test. Evaluation of the level of significance of the ob- served difference between the dosimetric parameters had been performed and $\mathrm{p}<0.05$ was considered as statistically significant.

\section{Results}

From the analyzed data of the 20 patients with a median age of 57 years, the mean volume of the PTV was $636.69 \pm 281.41 \mathrm{cc}$ (range; $368.15-1434.35 \mathrm{cc}$ ). In Table 2, the DVH parameters for the PTV and OARs were mentioned with mean value and standard deviation for all the cases. Analyzing all the VMAT plans, the mean value of total MU and the IMRT ratio was $741.50 \pm 135.50$ and $4.01 \pm 0.72$, respectively.

Figure 1 depicts the typical dose distribution of the beam arrangements in VMAT treatment plans with a color wash display ranging from $10 \mathrm{~Gy}$ to $50 \mathrm{~Gy}$ for an example case. The analysis of the volume of the OARs such as lungs and heart receiving low doses of the tune of $5 \mathrm{~Gy}, 10 \mathrm{~Gy}, 20 \mathrm{~Gy}$, and $30 \mathrm{~Gy}$, etc., revealed that 
Table 3 Summary of the quantitative analysis

\begin{tabular}{|c|c|c|c|c|c|c|c|c|}
\hline \multicolumn{2}{|c|}{$\begin{array}{l}\text { Dosimetric } \\
\text { parameters }\end{array}$} & \multirow[t]{2}{*}{$\begin{array}{l}\text { Scoring guideline } \\
\text { organ-at-risk } \\
\text { (QUANTEC) }\end{array}$} & \multicolumn{2}{|c|}{$\begin{array}{l}\text { Radiation- } \\
\text { induced } \\
\text { toxicity }\end{array}$} & \multicolumn{4}{|c|}{ Our study result } \\
\hline Type & Value & & $\begin{array}{l}\text { Toxicity } \\
\text { rate (\%) }\end{array}$ & Endpoint & $\begin{array}{l}\text { Mean } \\
\text { value }\end{array}$ & $\begin{array}{c}\text { Number of } \\
\text { patients } \\
\text { exceeding; } \\
\text { n (\%) }\end{array}$ & $\begin{array}{c}\text { Mean } \\
\text { difference }\end{array}$ & $\mathbf{p}$ \\
\hline \multirow[t]{5}{*}{$D_{\text {mean }}(G y)$} & 7 & Lung & 5 & $\begin{array}{l}\text { Symptomatic } \\
\text { pneumonitis }\end{array}$ & $13.23 \pm 2.35$ & $20(100)$ & 6.23 & 0.000 \\
\hline & 13 & & 10 & & & $10(50)$ & 0.23 & 0.666 \\
\hline & 20 & & 20 & & & 0 & - & \\
\hline & 24 & & 30 & & & 0 & - & \\
\hline & 27 & & 40 & & & 0 & - & \\
\hline $\mathrm{V}_{20 G \mathrm{~V}}(\%)$ & 30 & & $<20$ & & $25.24 \pm 4.72$ & $3(15)$ & -4.76 & 0.000 \\
\hline $\mathrm{V}_{256 y}(\%)$ & 10 & Heart & $<1$ & $\begin{array}{l}\text { Long-term } \\
\text { cardiac } \\
\text { mortality }\end{array}$ & $47.99 \pm 21.14$ & $19(95)$ & 37.99 & 0.000 \\
\hline $\mathrm{V}_{306 \mathrm{y}}(\%)$ & 46 & & $<15$ & Pericarditis & $35.82 \pm 16.32$ & $4(20)$ & -10.18 & 0.012 \\
\hline$D_{\text {mean }}(G y)$ & 26 & & $<15$ & Pericarditis & $24.44 \pm 8.51$ & $12(60)$ & -1.56 & 0.422 \\
\hline
\end{tabular}

QUANTEC: Quantitative analyses of normal tissue effects in the clinic; $\mathrm{D}_{\text {mean }}$ : Mean dose; $\mathrm{V}_{\mathrm{G} y}$ :The volume of the structure receiving a certain dose; Gy: Gray

there was a risk of complications after the radiotherapy treatment regimen according to the QUANTEC constraints. From the quantitative analysis of Figure 2, it was noted that the dose fall-off beyond the target region for the case of the combined lung was following a logarithmic pattern for the decrease in the average value of total volume $(\mathrm{V})$ encompassed with the increase in the dose (D) value and the dose fall-off in case of heart was following a linear curve; as $\mathrm{D} \propto 1 / \mathrm{V}$.

On analysis of DVH parameters of the main OARs from Table 3 based on QUANTEC, it was noted that $\mathrm{D}_{\text {mean }}$ of the combined bilateral lung was $13.23 \pm 2.35$ Gy. According to the scoring guidelines based on lung dose for symptomatic pneumonitis, for all the cases, the value of $\mathrm{D}_{\text {mean }}$ was significantly higher than $7 \mathrm{~Gy}$ with a $5 \%$ toxicity rate but the difference with 13 Gy was not significant and $50 \%$ of patients were exceeding the $10 \%$ toxicity rate in the VMAT plans. Similarly, for $\mathrm{V}_{20 \mathrm{~Gy}}, 85 \%$ of patients were below the value of $30 \%$ $(<20 \%$ toxicity rate) with a significant difference.

At the same time in DVH parameters of heart, $95 \%$ and $20 \%$ of the patients had exceeded the quoted value of $\mathrm{V}_{25 \mathrm{~Gy}}$ and $\mathrm{V}_{30 \mathrm{~Gy}}$ with a significant difference and the difference in the $\mathrm{D}_{\text {mean }}(24.44 \pm 8.51 \mathrm{~Gy})$ of the heart was not significantly different from 26 Gy with $60 \%$ patients exceeding the quoted mean dose in the VMAT plans.
The mean value of the combined NTCP from the dosimetric parameters of lungs and heart was $0.16 \pm 0.04$ and the median value was 0.17 ranging from 0.05 to 0.20 . Figure 3 depicts the NTCP values of each patient graphically. The NTCP value of 0.17 is consistent with the risk observed with the QUANTEC criteria where none of our patients crossed the $20 \%$ pulmonary morbidity risk (Table 3 ).

From Table 4, the observed value of RF in the lung was $0.61 \pm 0.13$ with a maximum and minimum value of 0.84 and 0.37 , respectively, which showed a mod-

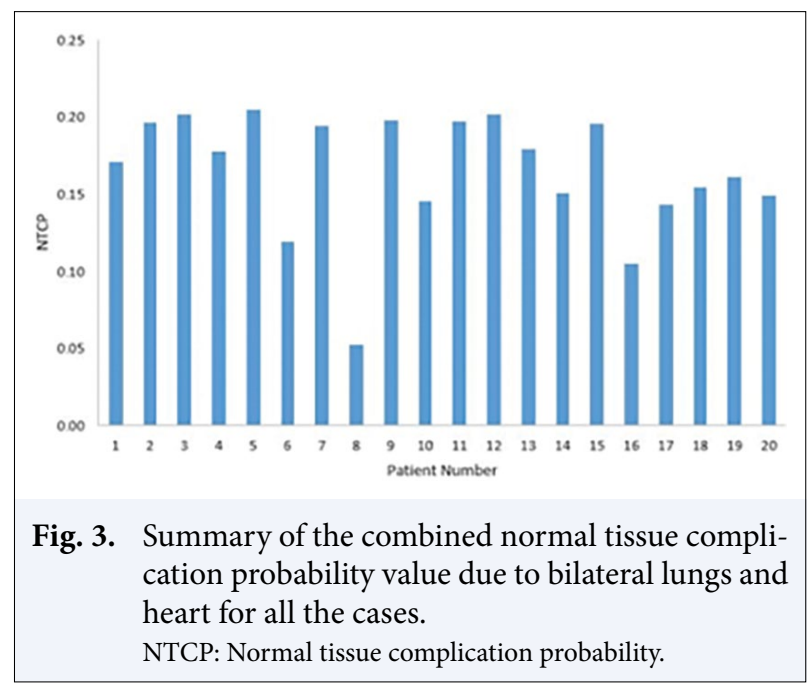


Table 4 Summary of the risk factor analysis in VMAT technique for esophageal cancer

\begin{tabular}{lcccc} 
Organ-at-risk & Tolerance dose (Gy) (Mean dose) & Endpoint & RF & RFC \\
\hline Lung & $20 \mathrm{~Gy}$ & Radiation pneumonitis & $0.61 \pm 0.13$ & $1.12+0.61$ \\
Heart & $26 \mathrm{~Gy}$ & Pericarditis & $0.86 \pm 0.43$ & $1.12+0.86$ \\
\hline
\end{tabular}

VMAT: Volumetric modulated arc therapy; RF: Risk factor; RFC: Risk factor conformity index

erate risk of complication as per the RFC method of evaluation. Similarly, in the case of the heart, the observed value of RF was $0.86 \pm 0.43$ with a maximum and minimum value of 1.46 and 0 , respectively, and the probability of risk for the particular organ was at high risk and the chances of complications were at higher side. With the observed value of CI as $1.12 \pm 0.07$, the value of RFC was $1.12+0.61$ and $1.12+0.86$ for lung and heart, respectively.

\section{Discussion}

Radiation-induced lung injury in the latent period is often asymptomatic. Subsequently, acute RP, due to appreciable endothelial cell loss in vascular tissues resulting in disrupted homeostasis in the pulmonary microenvironment, became most often clinically apparent after 2-6 months of the radiotherapy treatment. Second, radiation-induced lung fibrosis evolves between 6 and 24 months of post-treatment, which may occur permanent deterioration of lung function after a few years.[21] Radiation-induced lung toxicities are volume dependent. Reduced volume of exposed lung tissues with a smaller dose fractionation will reduce the probability of lung toxicity.[22]

Current treatment modalities introduced new radiotherapy techniques which improved the quality of treatment. VMAT is a widely used technique for esophageal malignancy delivering a non-uniform dose from multiple angles generating dose fluences throughout the gantry rotation with the aid of variable speed of gantry, MLC movements, and dose rate to create a very conformal dose to targets with minimal complication to surrounding OARs.[12,23-25]

In our study, the dosimetric parameters in the treatment of esophageal cancer patients were investigated and assessed by comparing our results to the QUANTEC guidelines, a summarized available published data for risk and toxicity assessment. We found that the VMAT plan is robust for both target and normal tissues with increasing target coverage and conformity. In esophageal malignancy, the critical OARs are the lungs, heart, and spinal cord. From the previous study, dosimetric parameters such as $\mathrm{D}_{\text {mean }}, \mathrm{V}_{20 \mathrm{~Gy}}$, and $\mathrm{V}_{30 \mathrm{~Gy}}$ seemed to be the closely associated important RFs for RP due to the significant damage of the lung subvolumes. The probability of RP was increased with the increase in the value of the dosimetric parameters.[26] In our study result (Table 3 ), the dosimetric parameters, for example, $\mathrm{D}_{\text {mean }}, \mathrm{V}_{20 \mathrm{~Gy}}$ of the lung, and heart were quite less according to the QUANTEC guidelines.

The probability of RP will increase with the coexistence of pulmonary complications. The dosimetric parameters obtained from the DVH analysis had been shown to influence and predict the occurrence of RP. Compared to 3D-CRT or IMRT, the incidence of late toxicities was quite lesser in the VMAT technique and using advanced radiotherapy techniques, we can achieve better outcomes and alleviate toxicities. Yang et al.[27] reported on 22 patients of esophageal malignancy treated with VMAT technique with an overall 2-year overall survival and failure-free survival rates of $56.0 \%$ with a concurrent CRT and the incidence of RP was much lower in VMAT group from 3D-CRT and IMRT groups because of the significantly lower dose bath in the lungs, comparing mean dose and $\mathrm{V}_{20 \mathrm{~Gy}}$ of the lung. Münch et al.[4] reported a study on 17 patients of esophageal cancer with VMAT technique showing $\mathrm{D}_{\text {mean }}, \mathrm{V}_{5 \mathrm{~Gy}}$ and $\mathrm{V}_{20 \mathrm{~Gy}}$ were lower than $3 \mathrm{D}$-CRT planning and $13 \%$ of patients of that group had postoperative pneumonia. From a previous study, it was shown that there was no such evidence of RP with a $\mathrm{V}_{5 \mathrm{~Gy}}>71 \%$ developed Grade 2 or higher lung toxicity. [11] Analyzing the Milano data for lung toxicity, it was reported that the value of $\mathrm{D}_{\text {mean }}$ and $\mathrm{V}_{30 \mathrm{~Gy}}$ should be in between 10-20 Gy and 10-15\%; if the $\mathrm{V}_{20 \mathrm{~Gy}}$ is $<25-30 \%$, the chances of late Grade 3 toxicity will be $<5-10 \%$ and if $\mathrm{V}_{13 \mathrm{~Gy}}$ is $<40 \%$, the probability of late Grade 2 toxicity will be $<10-20 \%$, respectively.[19] In our study, dosimetric parameters for the lung were within the limits prescribed by the Milano data for toxicity assessment.

Radiobiological analysis of a treatment plan serves as an important adjunct to a dosimetric evaluation in determining the overall quality of the treatment plan as well as complication rate to the OARs due to radiotherapy. Evaluation of the radiobiological parameters of a 
treatment plan with the help of dosimetric parameters is more comprehensive and rational. From the previous studies, it was demonstrated that radiobiological analysis supported that VMAT was a better choice because of more superior tumor control probability (TCP) and lower NTCP of lungs and heart compared with IMRT and other types of modalities. [3,25] Radiation-induced heart toxicities enhanced the probability of early radiation-induced lung function loss and using the combined heart and lung irradiation model for predicting the occurrence of RP, the risks of RP were greater than for the lung only model with a median NTCP value $14.2 \%$ in 50 Gy and $15.5 \%$ in 62.5 Gy dose prescription, respectively.[6] In our study, the median NTCP value was $17.43 \%$, slightly larger than the previous study increases the risk of RP. According to Nalbantov et al.,[5] the value of $\mathrm{D}_{\text {mean }}$ of heart was the confounding factor for predicting radiation-induced lung injury and $29.3 \%$ of patients from all groups where $44 \%$ of the cardiac comorbidity patients with $\mathrm{D}_{\text {mean }}$ of heart developed dyspnea more than Grade 2 after radiotherapy.

$\mathrm{CI}_{\mathrm{RTOG}}$ interpreted as target covering the reference isodose line with no information about the damage to the nearby critical organs and RF signified the degree of damage to a particular organ with the dosimetric parameters from a radiobiological point of view. The significance of $R F$ value as $R F \simeq 0,0.5$, and $\geq 1$ means low, moderate, and high- RFs, respectively. Combining both the parameters, RFC denotes the target coverage as well as a RF for nearby critical organs radiobiologically. [20] In our study, the value of $\mathrm{CI}_{\mathrm{RTOG}}$ and $\mathrm{RF}$ for lung and heart from Table 4 represented that the radiotherapy plans were highly conformal with a moderate risk of lung and heart toxicities.

\section{Conclusion}

Modern radiotherapy techniques with better precession such as VMAT technique may reduce the toxicity rate of the patient after radiotherapy but adverse effects are remaining causing the quality of life. Radiationinduced lung toxicity, an inevitable accompaniment to thoracic radiotherapy, depends on many parameters, for example, tumor location, functional status of the organ, total dose to the tumor, the irradiated volume of the critical organ nearby, and other so many factors. Dosimetric as well as radiobiological parameters such as $\mathrm{D}_{\text {mean }}, \mathrm{V}_{20 \mathrm{~Gy}}$, and NTCP may predict the probability of RP incidence but there is a still lack of evidence of oncological outcomes with a larger patient cohort, long-term follow-up with these predictive parameters at the same time. Therefore, more research is needed for a better understanding of the dosimetric and radiobiological model for the assessment of the radiationinduced lung injury and how to minimize the toxicity rate with optimum tumor control.

Peer-review: Externally peer-reviewed.

Conflict of Interest: All authors declared no conflict of interest.

Ethics Committee Approval: The current study is a retrospective data study. Therefore, the institutional ethical committee waived off for the ethical approval.

Financial Support: This study has received no financial support.

Authorship contributions: Concept - S.G., S.A., S.M., P.P.; Design - S.G., S.A., S.M.; Supervision - S.S., A.S., S.V., P.P.; Funding - None; Materials - None; Data collection and/ or processing - S.G., S.A., S.M.; Data analysis and/or interpretation - S.G., S.A., S.M., S.H.K.; Literature search - S.G., S.A., S.M.; Writing - S.G., S.A., S.M., S.H.K.; Critical review - S.G., S.A., S.M., S.H.K., S.S., A.S., S.V., P.P.

\section{References}

1. Madani I, de Ruyck K, Goeminne H, de Neve W, Thierens H, van Meerbeeck J. Predicting risk of radiation-induced lung injury. $J$ Thorac Oncol 2007;2(9):864-74.

2. Hirano Y, Onozawa M, Hojo H, Motegi A, Zenda S, Hotta K, et al. Dosimetric comparison between proton beam therapy and photon radiation therapy for locally advanced esophageal squamous cell carcinoma. Radiat Oncol 2018;13(1):23.

3. Wang L, Li C, Meng X, Li C, Sun X, Shang D, et al. Dosimetric and radiobiological comparison of external beam radiotherapy using simultaneous integrated boost technique for esophageal cancer in different location. Front Oncol 2019;9:674.

4. Münch S, Aichmeier S, Hapfelmeier A, Duma MN, Oechsner M, Feith M, et al. Comparison of dosimetric parameters and toxicity in esophageal cancer patients undergoing 3D conformal radiotherapy or VMAT. Strahlenther Onkol 2016;192(10):722-9.

5. Nalbantov G, Kietselaer B, Vandecasteele K, Oberije C, Berbee M, Troost E, et al. Cardiac comorbidity is an independent risk factor for radiation-induced lung toxicity in lung cancer patients. Radiother Oncol 2013;109(1):100-6.

6. Warren S, Partridge M, Carrington R, Hurt C, Crosby T, Hawkins MA. Radiobiological determination of dose escalation and normal tissue toxicity in definitive 
chemoradiation therapy for esophageal cancer. Int J Radiat Oncol Biol Phys 2014;90(2):423-9.

7. Bray F, Ferlay J, Soerjomataram I, Siegel RL, Torre LA, Jemal A. Global cancer statistics 2018: GLOBOCAN estimates of incidence and mortality worldwide for 36 cancers in 185 countries. CA Cancer J Clin 2018;68(6):394-424.

8. Lin JC, Tsai JT, Chang CC, Jen YM, Li MH, Liu WH. Comparing treatment plan in all locations of esophageal cancer: Volumetric modulated arc therapy versus intensity-modulated radiotherapy. Medicine (Baltimore) 2015;94(17):e750.

9. Zhang M, Wu AJ. Radiation techniques for esophageal cancer. Chin Clin Oncol 2017;6(5):45.

10. Roeder F, Nicolay NH, Nguyen T, Saleh-Ebrahimi L, Askoxylakis V, Bostel T, et al. Intensity modulated radiotherapy (IMRT) with concurrent chemotherapy as definitive treatment of locally advanced esophageal cancer. Radiat Oncol 2014;9:191.

11. Tonison JJ, Fischer SG, Viehrig M, Welz S, Boeke S, Zwirner $\mathrm{K}$, et al. Radiation pneumonitis after intensity-modulated radiotherapy for esophageal cancer: Institutional data and a systematic review. Sci Rep 2019;9(1):2255.

12. Choi KH, Kim J, Lee SW, Kang YN, Jang H. Dosimetric comparison between modulated arc therapy and static intensity modulated radiotherapy in thoracic esophageal cancer: A single institutional experience. Radiat Oncol J 2018;36(1):63-70.

13. Martini S, Arcadipane F, Strignano P, Spadi R, Contu V, Fiandra C, et al. Volumetric modulated arc therapy (VMAT) in the treatment of esophageal cancer patients. Med Oncol 2018;35(12):150.

14. Kataria T, Govardhan HB, Gupta D, Mohanraj U, Bisht SS, Sambasivaselli R, et al. Dosimetric comparison between volumetric modulated arc therapy (VMAT) vs intensity modulated radiation therapy (IMRT) for radiotherapy of mid esophageal carcinoma. J Cancer Res Ther 2014;10(4):871-7.

15. Safran H, Co-Chair RO, Hong TS, Hospital MG, Cochair RO, Haddock M, et al; Radiation Therapy Oncology Group RTOG 1010. A phase III trial evaluating the addition of trastuzumab to trimodality treatment of HER2-overexpressing esophageal adenocarcinoma; 2010. Available at: https://clinicaltrials.gov/ProvidedDocs/90/NCT01196390/Prot_SAP_000.pdf. Accessed Feb 22, 2022.

16. Bradley J. NRG Oncology Ecog-Acrin RTOG 1106/ Acrin 6697. Randomized phase II trial of individualized adaptive radiotherapy using during-treat- ment FDG-PET/CT and modern technology in locally advanced non-small cell lung cancer (NSCLC); 2016. Available at: https://clinicaltrials.gov/ProvidedDocs/28/NCT01507428/Prot_SAP_000.pdf. Accessed Feb 22, 2022.

17. Feuvret L, Noël G, Mazeron JJ, Bey P. Conformity index: A review. Int J Radiat Oncol Biol Phys 2006;64(2):333-42.

18. Petrova D, Smickovska S, Lazarevska E. Conformity index and homogeneity index of the postoperative whole breast radiotherapy. Open Access Maced J Med Sci 2017;5(6):736-9.

19. Lee S, Cao YJ, Kim CY. Physical and radiobiological evaluation of radiotherapy treatment plan, Available at: https://www.intechopen.com/chapters/49039. Accessed Sep 17, 2015.

20. Ansari S, Zope M, Yadav N. A new method for risk factor assessment of organs at risk including conformity index in radiotherapy treatment plan. J Radiother Pract 2021;20:144-52.

21. Beach TA, Groves AM, Williams JP, Finkelstein JN. Modeling radiation-induced lung injury: Lessons learned from whole thorax irradiation. Int $\mathrm{J}$ Radiat Biol 2020;96(1):129-44.

22. Williams JP, Newhauser W. Normal tissue damage: its importance, history and challenges for the future. $\mathrm{Br} \mathrm{J}$ Radiol 2019;92(1093):20180048.

23. Abbas AS, Moseley D, Kassam Z, Kim SM, Cho C. Volumetric-modulated arc therapy for the treatment of a large planning target volume in thoracic esophageal cancer. J Appl Clin Med Phys 2013;14(3):4269.

24. Hawkins MA, Bedford JL, Warrington AP, Tait DM. Volumetric modulated arc therapy planning for distal oesophageal malignancies. Br J Radiol 2012;85(1009):44-52.

25. Yin $\mathrm{L}, \mathrm{Wu} \mathrm{H}$, Gong J, Geng JH, Jiang F, Shi AH, et al. Volumetric-modulated arc therapy vs. c-IMRT in esophageal cancer: A treatment planning comparison. World J Gastroenterol 2012;18(37):5266-75.

26. Liang B, Yan H, Tian Y, Chen X, Yan L, Zhang T, et al. Dosiomics: Extracting 3D spatial features from dose distribution to predict incidence of radiation pneumonitis. Front Oncol 2019;9:269.

27. Yang H, Feng C, Cai BN, Yang J, Liu HX, Ma L. Comparison of three-dimensional conformal radiation therapy, intensity-modulated radiation therapy, and volumetric-modulated arc therapy in the treatment of cervical esophageal carcinoma. Dis Esophagus 2017;30(2):1-8. 